\title{
NARRATIVAS DE TORCEDORES ORGANIZADOS PRATICANTES DE ARTES MARCIAIS ACERCA DA VIOLÊNCIA NO FUTEBOL PARANAENSE
}

\author{
Recebido em: 02/09/2019 \\ Aprovado em: 06/03/2020
}

Licença: @) $(1) \Theta$

Jonathan Rocha Oliveira 1

Pauline Peixoto Iglesias Vargas2

André Mendes Capraro3

Gustavo Elias Zaniol4

Universidade Federal do Paraná (UFPR)

Curitiba - PR - Brasil

RESUMO: Este estudo buscou investigar possíveis relações entre a prática de Artes Marciais e a violência nas Torcidas Organizadas no futebol paranaense. Utilizaram-se entrevistas de História Oral pautadas na prática de Artes Marciais por torcedores organizados, com vivências no contexto da violência no futebol curitibano. As narrativas foram realizadas com um integrante torcidas organizadas: Os Fanáticos, Império Alviverde e Fúria Independente. Evitando generalizações, sugere-se que as narrativas apontam que uma parcela (minoritária) dos torcedores organizados procura se desenvolver nas Artes Marciais para utilizar suas técnicas nos confrontos entre torcidas. Os discursos também alertam para a importância dos mestres/instrutores de Artes Marciais na orientação e na conduta de seus alunos. Portanto, identificaram-se algumas aproximações entre violência, Torcida Organizada e Artes Marciais.

PALAVRAS-CHAVE: Torcidas Organizadas. Artes Marciais. Violência.

\section{NARRATIVES OF ORGANIZED SUPPORTERS PRACTICING MARTIAL ARTS ABOUT THE VIOLENCE IN THE PARANAENSE FOOTBALL}

ABSTRACT: This study sought to investigate possible relationships between the practice of Martial Arts and violence in organized football in Paraná. Oral History interviews were used based on the practice of Martial Arts by organized fans, with experiences in the context of violence in Curitiban's football. The narratives were performed with an organized twisted member: Os Fanáticos, Império Alviverde e Fúria Independente. Avoiding generalizations, it is suggested that the narratives point out that a (minority) portion of the organized fans seek to develop in martial arts to use their techniques in clashes between fans. The speeches also alert to the importance of martial

\footnotetext{
1 Mestrando em Educação Física (UFPR) - Linha de pesquisa: Aspectos socioculturais do Esporte e Lazer. Graduado em Bacharelado em Educação Física (UFPR).

2 Doutoranda em Educação Física (UFPR) - Linha de pesquisa: Aspectos socioculturais do Esporte e Lazer.

3 Doutor em História (UFPR) com Estágio Pós-Doutoral na Università Ca’ Foscari Di Venezia.

4 Mestrando em Educação Física (UFPR) - Linha de pesquisa: Aspectos socioculturais do Esporte e Lazer. Graduado em Licenciatura em Educação Física (UFPR).
} 
Narrativas de Torcedores Organizados Praticantes de Artes Marciais Acerca da Violência no Futebol

Jonathan Rocha Oliveira, Pauline Peixoto I. Vargas, André Mendes Capraro e Gustavo Elias Zaniol

arts masters / instructors in guiding and conducting their students. Therefore, some approaches were identified between violence, Organized Cheering and Martial Arts.

KEYWORDS: Organized Cheerleaders. Martial Arts. Violence.

\section{Introdução}

A violência no futebol é uma manifestação social, paulatinamente, incrustada no cotidiano dos torcedores em diversas partes do mundo. No Brasil, o fenômeno se intensificou gradativamente nos últimos anos, tornando-se um assunto recorrente na mídia5 (TOLEDO, 1996; SANTOS; CAPRARO; LISE, 2014; CASTRO, 2014 apud CORIOLANO; CONDE, 2016; UOL, 2017) e no meio acadêmico (REIS, 2006; HANSEN, 2007; HOLLANDA; AZEVEDO; QUEIROZ, 2014; CORIOLANO; CONDE, 2016; MURAD, 2017). Por conta disso, foram tomadas algumas medidas de combate à violência no futebol - como a criação do Estatuto de Defesa do Torcedor em 2003 (MEZZADRI et. al., 2011). No entanto, tais ações e discussões ainda não foram suficientes para prevenir as corriqueiras cenas fatídicas de brigas, conflitos e confusões entre torcedores. Somente no ano de 2017, foram registrados 104 episódios de violência relacionados a torcedores de futebol no Brasil, que resultaram em 11 mortes (EL PAÍS BRASIL, 2017).

$\mathrm{Na}$ última década, alguns dos episódios mais brutais envolveram torcedores de clubes da cidade de Curitiba, no estado do Paraná, como a invasão de torcedores do Coritiba Football-Club no Couto Pereira em 2009 (BONIN, 2011; SANTOS CAPRARO; LISE, 2014; GUILHON 2017) e a briga generalizada entre torcedores do Clube Athlético Paranaense e do Clube de Regatas Vasco da Gama, na Arena Joinville em 2013 (CORIOLANO; CONDE, 2016; LOPES; REIS, 2017). Em ambos os casos,

5 O jornal "Lance" apresentou uma reportagem contemplando 15 casos emblemáticas de violência nos estádios brasileiros entre 2017 e 2018. Disponível em: http://www.lance.com.br/futebolnacional/marca-negativa-relembre-episodios-violencia-estadios-brasil.html. Acesso em: 29 ago. 2019.

licere, Belo Horizonte, v.23, n.2, jun/2020. 
Narrativas de Torcedores Organizados Praticantes de Artes Marciais Acerca da Violência no Futebol

Jonathan Rocha Oliveira, Pauline Peixoto I. Vargas, André Mendes Capraro e Gustavo Elias Zaniol

observou-se o envolvimento de integrantes de Torcidas Organizadas. Por conta de episódios como esses tais agremiações, de modo geral, são frequentemente responsabilizadas pela violência, dentro e fora de campo (TOLEDO, 1996; HOLLANDA, AZEVEDO; QUEIROZ, 2014; GUILHON, 2017; MURAD, 2017). Em contrapartida, o sociólogo Maurício Murad (2017) sugere que essa perspectiva é equivocada e generalista, pois a violência é praticada por uma minoria "perigosa" das Torcidas Organizadas.

Destaca-se, ainda, a presença de praticantes de Artes Marciais6 nesses confrontos citados à título de exemplo - O lutador de MMA Alexandre "Sangue" foi flagrado na invasão de campo da torcida do Coritiba Foot-Ball Club no jogo contra o Fluminense Foot-ball Club em 20097; após o ocorrido na Arena Joinville em 2013, a Policia Civil do Rio de Janeiro identificou a presença de lutadores de Artes Marciais8 participando de uma briga entre os torcedores organizados do Athlético e do Vasco protagonizados por torcedores organizados. É neste aspecto que os esforços deste estudo foram concentrados, ou seja, nas possíveis aproximações entre as práticas de Artes Marciais e a violência de parte dos torcedores organizados. Para tanto, é imprescindível apresentar algumas contribuições teóricas que fomentam possibilidades para esta relação. Vale a ressalva de que houve um afastamento dos critérios próprios para estabelecê-la o que é ou não violento, que geralmente, estão balizados por experiências pessoais e sensibilidades próprias (LISE, 2018).

Alguns autores (TOLEDO, 2010; SILVA et al., 2010) comentam que as Torcidas Organizadas brasileiras - sobretudo, aquelas com maior número de membros

Considerando as divergências conceituais entre Arte Marcial, Luta e Esportes de Combate, optou-se por adotar o termo "Arte Marcial", de acordo com Correia e Franchini (2010).

7 Reportagem exibida no Jornal da noite da TV Globo em 9/12/2009 (3 dias após o ocorrido). Disponível em http://www.youtube.com/watch?v=3MVliyyInQg. Acesso em: 29 ago. 2019.

8 Disponível em: http://oglobo.globo.com/esportes/campeonato-brasileiro-2013/vascainos-envolvidosem-briga-em-joinville-sao-identificados-11032774. Acesso em: 29 ago. 2019.

licere, Belo Horizonte, v.23, n.2, jun/2020. 
Narrativas de Torcedores Organizados Praticantes de Artes Marciais Acerca da Violência no Futebol Jonathan Rocha Oliveira, Pauline Peixoto I. Vargas, André Mendes Capraro e Gustavo Elias Zaniol

- apresentam uma dinâmica funcional hierarquizada, administrativa e no formato empresarial. Nestes casos, o oferecimento de diversos serviços para seus membros (e alguns destes para comunidade externa), em especial, a prática de Artes Marciais (MURAD, 2017). A título de exemplo, Viviane Hansen mostra em sua dissertação, a existência da Academia Templo da Caveira situada nas dependências da sede da Torcida Organizada Os Fanáticos - TOF - (HANSEN, 2007).

Nessa lógica existencial de espaços destinados a prática de Artes Marciais para, preferencialmente, integrantes das Torcidas Organizadas dentro de suas áreas privadas, é possível que alguns destes praticantes possam estar utilizando as técnicas desenvolvidas nessas academias em confrontos físicos com outros torcedores de futebol (MURAD, 2017). Tal dinâmica também é abordada pelos veículos de comunicação. Em uma reportagem9 televisiva, um torcedor organizado narra algumas lógicas de funcionamento, durante os 10 anos em que integrou uma Torcida Organizada, admitindo ser praticante de Artes Marciais e participar das brigas e conflitos que assolam o esporte e a sociedade brasileira.

Por outro lado, entende-se que a prática das Artes Marciais apresenta outras finalidades. A essência das Artes Marciais está baseada na relação do ensinamento de princípios gerais que possam ser aplicados nas lutas e na vida pessoal (FETT; FETT, 2009). Para Correia e Franchini (2010), as pessoas visam se engajar nesses tipos de práticas para melhorar a saúde e a qualidade de vida, disciplinar crianças e jovens, desenvolver a defesa pessoal, uma filosofia de vida, espiritualidade e preconizar a paz. Esses objetivos apontados pelos autores estão atrelados aos aspectos que definem essas práticas como Esportes de Combate, entretanto, quando se trata dos casos citados de alguns torcedores organizados, as práticas apresentam características da marcialidade,

9 Conteúdo exibido durante o programa Brasil Urgente da TV Bandeirantes-SP. Disponível em: http://videos.band.uol.com.br/13185046/exclusivo-ex-integrante-denuncia-crimes-de-torcidasorganiz.html. Acesso em: 27 jul. 2019.

licere, Belo Horizonte, v.23, n.2, jun/2020. 
Narrativas de Torcedores Organizados Praticantes de Artes Marciais Acerca da Violência no Futebol

Jonathan Rocha Oliveira, Pauline Peixoto I. Vargas, Andre Mendes Capraro e Gustavo Elias Zaniol

ou seja, voltadas a guerra e ao confronto. É neste último aspecto (Arte Marcial) que o presente estudo concentrou o seu escopo de análise.

Considerando os casos destacados nesta seção introdutória, é possível que a cidade de Curitiba tenha se tornado um dos polos da violência entre torcedores no futebol brasileiro. Antes da virada do século, a capital paranaense já era palco de uma série de contundentes confrontos físicos entre praticantes de Artes Marciais em quaisquer locais em que houvesse oportunidade, seja em vias públicas ou privadas (PASSOS et. al., 2014). Em vista disso, justifica-se a abordagem das Torcidas Organizadas da cidade como objeto de análise.

Destacada a pertinência de se analisar possíveis aproximações entre a prática de Artes Marciais e a violência nas Torcidas Organizadas na cidade de Curitiba, alguns meios de comunicação buscam desvelar essa questão por meio de reportagens. No que tange o meio acadêmico, a discussão das Artes Marciais nas Torcidas Organizadas tanto no âmbito regional quanto nacional - ainda é incipiente e pouco explorada. Nesse sentido, o que sabe sobre a atuação dos mestres/instrutores das Artes Marciais em relação as Torcidas Organizadas e a opinião desses praticantes/torcedores organizados acerca da violência no futebol?

Para auxiliar na resolução dessas questões, esse estudo visa apresentar narrativas de torcedores organizados com vivências nas Artes Marciais e, a partir disso, analisar seus discursos para compreender melhor esses fenômenos. Busca-se, ainda, constituir novas fontes de pesquisa e oferecer subsídios para futuras investigações acerca dessa temática. Para tanto, utilizou-se entrevistas de História Oral com agentes envolvidos nesse prisma e, ainda, buscou-se o embasamento teórico em referenciais bibliográficos e documentais correlatos.

licere, Belo Horizonte, v.23, n.2, jun/2020. 
Narrativas de Torcedores Organizados Praticantes de Artes Marciais Acerca da Violência no Futebol

Jonathan Rocha Oliveira, Pauline Peixoto I. Vargas, André Mendes Capraro e Gustavo Elias Zaniol

Cabe ressaltar que analisar essa temática requer cautela para evitar generalizações acerca dos torcedores organizados que praticam Artes Marciais. Não compete à esta pesquisa apontar uma relação de causa e efeito entre torcedores organizados praticantes de Artes Marciais e a violência presente nas Torcidas Organizadas. Reproduzir saberes deterministas, sem embasamento teórico e/ou amostra de análise suficiente, pode sugerir uma compreensão equivocada acerca de torcedores organizados com vivências nas Artes Marciais.

\section{Procedimentos Metodológicos}

Este estudo apoiou-se nos pressupostos da História Oral como método de investigação e, ainda, consultou documentos e referenciais bibliográficos correlatos à temática. Para Verena Alberti a História Oral é definida como:

um método de pesquisa (histórica, antropológica, sociológica etc.) que privilegia a realização de entrevista com pessoas que participaram de, ou testemunharam, acontecimentos, conjunturas, visões de mundo, como forma de se aproximar do objeto de estudo. Como consequência, o método da história oral produz fontes de consulta (as entrevistas) para outros estudos (ALBERTI, 2013, p.24).

As fontes orais desta pesquisa foram submetidas a uma análise de discurso fundamentada por Bardin (2011), atrelada a outros documentos como ferramenta investigativa, sobretudo para reconstruir o conteúdo implícito nas narrativas dos entrevistados (ROSENTHAL, 2014). Segundo Amado e Ferreira (2006, p. 09), “A pesquisa com fontes orais apóia em pontos de vista individuais, expressos nas entrevistas; estas são legitimadas como fontes".

A História Oral como objeto de estudo do pesquisador é constituída por meio da memória dos entrevistados (AMADO; FERREIRA, 2006: 10). Para Michael Pollak (1992), a memória é fundamental na construção do sentimento de identidade, tanto individual como coletiva. Este mesmo autor sugere, ainda, que a memória pode ser 
Narrativas de Torcedores Organizados Praticantes de Artes Marciais Acerca da Violência no Futebol

Jonathan Rocha Oliveira, Pauline Peixoto I. Vargas, Andre Mendes Capraro e Gustavo Elias Zaniol

observada como um fenômeno produzido em referência aos outros, ou seja, refere-se a imagem que este indivíduo busca transmitir para seu grupo social pertencente (neste caso, as Torcidas Organizadas), sentindo-se representado e permitindo a construção de significados na vida deste sujeito.

Vale lembrar que os conteúdos obtidos com as entrevistas não devem ser tidos como uma verdade absoluta, mas sim como a forma com que sujeitos que viveram certa realidade a relatam e a significam, uma vez que "[...] o conteúdo do que lembramos torna-o, da mesma forma, singularmente pessoal: incluem detalhes pormenorizados e íntimos de acontecimentos, relacionamentos e sentimentos do passado" (LOWENTHAL, 1998, p. 79).

Foram realizadas três entrevistas, por meio de um roteiro semiestruturado de perguntas abertas pautadas pelos seguintes eixos temáticos: experiências na Torcida Organizada e nas Artes Marciais; envolvimento ou vivência em confrontos entre torcedores; possíveis relações entre Arte Marcial e a violência nas Torcidas Organizadas; violência no futebol. A escolha dos entrevistados seguiu os seguintes critérios de inclusão: 1) indivíduos que integram ou integraram uma Torcida Organizada da cidade de Curitiba, sendo elas: Torcida Os Fanáticos (TOF), do Clube Atlético Paranaense); Torcida Organizada Império Alviverde (IAV) do Coritiba Football Club) e a Torcida Fúria Independente (TFI) do Paraná Clube; 2) sujeitos que praticam ou praticaram algum tipo de arte marcial. Como critério de exclusão, integrantes de Torcidas Organizadas situadas em Curitiba, mas que representam clubes de outras regiões e estados brasileiros (fato comum no estado do Paraná).

Todos os entrevistados assinaram o Termo de Consentimento Livre

licere, Belo Horizonte, v.23, n.2, jun/2020. 
Esclarecido10 (TCLE) e solicitaram anonimato dos seus relatos. Sendo assim, este estudo os identificará como: "entrevistado TOF"; "entrevistado IAV"; "entrevistado TFI". O local de gravação das entrevistas foi escolhido previamente com os entrevistados de acordo com suas respectivas preferências. A duração média das entrevistas foi de uma hora. $\mathrm{O}$ meticuloso processo de passagem do oral para a forma escrita foi baseado na transcrição, que constitui a "[...] primeira versão escrita do depoimento [...]", base de trabalho das etapas posteriores (ALBERTI, 2013, p. 282). O último processo, que antecedeu a análise das entrevistas, foi a edição, no qual foram realizadas pequenas alterações nos relatos para melhor adequar a transcrição à atividade da leitura.

\section{As Torcidas Organizadas e a Violência no Futebol}

O futebol é um esporte que atrai adeptos e, muitas vezes, estes se reúnem, a priori, para torcer por seus clubes, formando agrupamentos de torcedores. No Brasil, boa parte desses agrupamentos constituem o fenômeno das Torcidas Organizadas, corroborando com a legislação federal brasileira, estabelecida pelo Estatuto de Defesa do Torcedor. De acordo com o documento, uma Torcida Organizada pode ser definida como uma instituição privada com a finalidade de torcer e apoiar uma entidade esportiva:

Considera-se torcida organizada, para os efeitos desta lei, a pessoa jurídica de direito privado ou existente de fato, que se organize para o fim de torcer e apoiar entidade de prática esportiva de qualquer natureza ou modalidade (BRASIL, 2013).

${ }_{10}$ Com a finalidade de homologar a pesquisa, o projeto que a gerou foi aprovado pelo Comitê de Ética em Pesquisa do Instituto de Ciências Humanas da Universidade de Brasília - CEP/IH, mediante o parecer consubstanciado número 1.469.110. A inscrição do projeto junto ao Comitê Nacional de Ética em Pesquisa (CONEP) pode ser localizada no site "Plataforma Brasil" a partir do número de registro: 51225615.5.0000.5540.

licere, Belo Horizonte, v.23, n.2, jun/2020. 
Narrativas de Torcedores Organizados Praticantes de Artes Marciais Acerca da Violência no Futebol Jonathan Rocha Oliveira, Pauline Peixoto I. Vargas, André Mendes Capraro e Gustavo Elias Zaniol

No entanto, outras características estão sendo atribuída ao status destas agremiações, sobretudo, a partir dos anos de 1990. Nessa época, as Torcidas Organizadas ganharam maior destaque na opinião pública e mídia - sobretudo nas páginas policiais - por conta do frequente envolvimento em brigas e conflitos (CAVALVCANTI SOUZA; CAPRARO, 2013). São consideradas como o fio condutor da violência no futebol brasileiro por muitos especialistas da mídia (SANTOS; CAPRARO; LISE, 2014) e do meio acadêmico (HANSEN, 2007; REIS, 2006; HOLLANDA; AGUILAR, 2017; LOPES; REIS, 2017; MURAD). Alguns autores (TOLEDO, 1996; HANSEN, 2007; HOLLANDA; AZEVEDO; QUEIROZ, 2014; GUILHON, 2017; MURAD, 2017) sugerem que a questão é tratada pelos veículos de comunicação, muitas vezes, de modo sensacionalista e sem o devido conhecimento, por vezes, exacerbando o fenômeno da violência nas agremiações (REIS, 2006). Essa rotulação caracteriza a identidade das Torcidas Organizadas em sua totalidade como agrupamentos de indivíduos transgressores.

O fenômeno da violência entre torcedores também tomou atenção do Estado, que passou a atuar no combate à violência no universo futebolístico (HANSEN, 2007; BONIN et al, 2011; MEZZADRI et. al., 2011) como controlador e repressor da violência dentro e fora das praças esportivas, principalmente, após a elaboração do Estatuto de Defesa do Torcedor, entre outras ações, embora a eficácia dessas medidas ainda seja questionável (LOPES; REIS, 2017).

Em um primeiro momento, o artigo $1^{\circ}$-A do Estatuto de Defesa do Torcedor atribui a responsabilidade preventiva da violência, em prol da segurança do evento, aos principais grupos envolvidos nos eventos esportivos.

A prevenção da violência nos esportes é de responsabilidade do poder público, das confederações, federações, ligas, clubes, associações ou entidades esportivas, entidades recreativas e associações de torcedores, inclusive de seus respectivos dirigentes, bem como daqueles que, de qualquer forma, promovem, organizam, coordenam ou participam dos

licere, Belo Horizonte, v.23, n.2, jun/2020. 
eventos esportivos [...] Parágrafo único. A torcida organizada deverá manter cadastro atualizado de seus associados ou membros (BRASIL, 2013).

Observa-se que o documento aponta implicitamente para as Torcidas Organizadas - "entidades recreativas e associação de torcedores" - como um dos agentes responsáveis pela prevenção da violência. A omissão acerca das Torcidas Organizadas nesse tema da legislação corrobora com as afirmações de alguns autores (TOLEDO, 1996, REIS 2006) que, de modo geral, apontam para a negligência que as autoridades públicas do esporte tratam a inclusão das Torcidas Organizadas nas discussões e elaborações de políticas públicas de combate a violência no futebol.

A primeira citação ao termo "Torcida Organizada" no que tange a segurança do torcedor discorre acerca das punições as transgressões cometidas por membros das associações de torcedores. O documento correlaciona, exclusiva e explicitamente, esses grupos às Torcidas Organizadas.

[...] A torcida organizada que, em evento esportivo, promover tumulto; praticar ou incitar a violência; ou invadir local restrito aos competidores, árbitros, fiscais, dirigentes, organizadores ou jornalistas será impedida, assim como seus associados ou membros, de comparecer a eventos esportivos pelo prazo de até três anos. [...] torcida organizada responde civilmente, de forma objetiva e solidária, pelos danos causados por qualquer dos seus associados ou membros no local do evento esportivo, em suas imediações ou no trajeto de ida e volta para o evento (BRASIL, 2013).

De fato, é sabido que as Torcidas Organizadas possuam responsabilidade pelos atos transgressores de seus membros, embora devam ser incluídas nos debates acerca da elaboração de soluções para a violência no futebol. Salienta-se que esta tolerância das Torcidas Organizadas com a violência não é novidade, haja vista que Toledo (1996) aponta, já na década de 1990, que estas agremiações manifestam:

[...] tolerância e certa conivência das elites das Torcidas Organizadas com esta violência, concomitantemente buscam uma determinada legitimidade e visibilidade dentro do universo do futebol profissional e da própria sociedade (TOLEDO, 1996, p. 122).

licere, Belo Horizonte, v.23, n.2, jun/2020. 
Embora a violência, a intolerância e as brigas entre torcedores de futebol, sejam comuns atualmente, já se manifestavam - ainda que sem maiores consequências - desde a época do amadorismo, anterior aos anos de 1930 (TOLEDO, 2010). Por conta disso, muitos torcedores organizados são, por vezes, de modo simplista e generalizado, categorizados como violentos, gangues (TOLEDO, 1996; MURAD, 2017). No entanto, conforme aponta Murad (2017), a violência entre torcedores, especialmente os torcedores organizados no Brasil, é praticada por uma minoria reincidente, perigosa e via de regra - impune.

Apesar da ocorrência de muitos confrontos entre torcedores de clubes rivais, as querelas podem acontecer também entre torcedores de um mesmo clube, ou seja, em determinadas situações as rivalidades são "intraclube" e resultam das disputas simbólicas e materiais pelo controle das arquibancadas (HOLLANDA; AGUILAR, 2017), como a disputa pelo poder e o status de mais influente torcida entre a TOF e a Ultras, ambas do Clube Athlético Paranaense, apontadas por Mosko; Moletta Jr. e Freitas Júnior (2000).

Seguindo nesta direção, Toledo (1996) e Guilhon (2017) sugerem uma relação íntima dos torcedores organizados com a política, pública e privada (de seus clubes11), motivados por interesses pessoais e coletivos. De fato, as Torcidas Organizadas são constituídas e caracterizadas por lógicas de disputas por poder simbólico, reconhecimento social (TOLEDO, 1996; 2010) e “expressam determinados padrões comportamentais presentes na sociabilidade da vida cotidiana" (GUILHON, 2017: p. 83). Esses agrupamentos passam a fomentar, também, uma

11 O Jornal Nacional exibiu uma reportagem apontando que o então presidente do Vasco da Gama, Eurico Miranda, empregava no clube membros de uma grande TO vascaína (Força Jovem) que estava proibida de frequentar estádios. https:/globoesporte.globo.com/futebol/times/vasco/noticia/relatorio-do-gepe-identifica-membros-deorganizada-suspensa-trabalhando-no-vasco.ghtml. Acesso em: 27 ago. 2019.

licere, Belo Horizonte, v.23, n.2, jun/2020. 
Narrativas de Torcedores Organizados Praticantes de Artes Marciais Acerca da Violência no Futebol

Jonathan Rocha Oliveira, Pauline Peixoto I. Vargas, Andre Mendes Capraro e Gustavo Elias Zaniol

identidade torcedora (TOLEDO, 2010) e entre as diversas virtudes elementares de pertencimento e representação, a virilidade e a autoafirmação tornam-se características de uma nova configuração simbólica de torcedores organizados. Tal aspecto pode ser observado na construção dos símbolos de representação (mascotes, vestimentas e adereços) das Torcidas Organizadas, bem como em suas vestimentas, com semblantes mais agressivos, ferozes, imponentes enfurecidos e musculosos (TOLEDO, 1996; HANSEN 2007; GUILHON, 2017). Segundo Toledo (1996: p. 57), [...] "assumir-se enquanto membro de um Torcida Organizada é, sobretudo, assumir seus símbolos e marcas."

Reis (2006) afirma que a identidade simbólica na cultura esportiva pode resultar em ações transgressoras, embora a autora não mencione as Torcidas Organizadas. Concomitantemente, a "cultura das arquibancadas" (HOLLANDA; AGUILAR, 2017) no futebol é incrustrada por valores de supremacia, denegação do outro, auto excitação da virilidade e masculinidade seja atraente para os jovens rapazes. Contudo, diversos autores (TOLEDO, 1996; HANSEN, 2007; MURAD, 2017) destacam certa heterogeneidade com relação ao gênero, faixa etária, grau de instrução nos torcedores de futebol de modo geral e, também, nos torcedores organizados.

Compreender o comportamento de um torcedor de futebol instiga refletir sobre a origem da interação entre cidadão e futebol, bem como suas implicações. Para Toledo (1996) torcer por um clube de futebol é, a priori, participar ativamente da vida social. Esta participação começa pela escolha, que apesar de não ser uma regra, costuma ser feita ainda na infância e muitas vezes por influência das pessoas mais próximas ao indivíduo, como amigos, familiares ou até mesmo escolha individual (TOLEDO, 1996).

Ainda neste contexto, ódio, paixão, tristeza, euforia e cólera são emoções experimentadas por torcedores de futebol, níveis distintos e subjetivos de intensidade 
Narrativas de Torcedores Organizados Praticantes de Artes Marciais Acerca da Violência no Futebol

Jonathan Rocha Oliveira, Pauline Peixoto I. Vargas, Andre Mendes Capraro e Gustavo Elias Zaniol

(HOLLANDA; AGUILAR, 2017). Para Norbert Elias e Eric Dunning (1992), o futebol é capaz de despertar ou elevar tensões e sensações catárticas, até então contidas pela intolerância social à violência. Ainda segundo os referidos autores, essas manifestações violentas ocorrem devido à falta de "autodomínio" - autocontrole - do próprio indivíduo e uma pessoa incapaz de se autocontrolar, constitui um perigo para os outros e, também, para si (ELIAS; DUNNING, 1992).

Nesta direção, Cavalcanti; Souza e Capraro (2013) sugerem que tais sensações de "tensão-excitação" proporcionadas pelo futebol, podem gerar uma ruptura do comportamento socialmente aceito, desencadeando atos de violência. Alguns torcedores vislumbram o esporte como um dos poucos espaços sociais em que determinadas sensações de excitação podem ser alcançadas com maior nível de tolerância.

Esta tolerância com o descontrole emocional pode atrair indivíduos com outras finalidades para além do torcer futebolístico, ou seja, com uma perspectiva deliberada para condutas violentas. A partir disso, permite-se pensar um paradigma da violência (WIEVIORKA, 1997) no futebol, o qual incide em manifestações transgressoras corriqueiramente dentro e fora dos estádios de futebol.

Coriolano e Conde (2016) tratam o tema como uma questão da psicologia, apontando a violência no futebol como uma manifestação multifatorial de agressividade, formada por componentes de comportamento (agressão física e verbal), cognição (hostilidade) e emoção (raiva). Para os autores, o nível de fanatismo de um torcedor por seu clube, pode ser correlacionado com todas estas dimensões da agressividade abordadas por eles. O fanatismo representa um envolvimento emocional demasiado de um torcedor no futebol, podendo ser também um dos fatores inerentes entre as ações violentas e o esporte. Compreende-se que a violência também possa se 
Narrativas de Torcedores Organizados Praticantes de Artes Marciais Acerca da Violência no Futebol

Jonathan Rocha Oliveira, Pauline Peixoto I. Vargas, André Mendes Capraro e Gustavo Elias Zaniol

manifestar nos apaixonados que se deixam levar pelo "calor de um jogo" ou de uma discussão e "perdem a cabeça” (BONIN et. al., 2011, p. 165).

O Brasil possui cerca de dois milhões de membros integrantes de 700 Torcidas Organizadas (MURAD, 2017) e esse número expressivo de torcedores organizados no país sugere uma dificuldade em identificar o perfil de todos esses indivíduos. Por outro lado, Cavalcanti et. al. (2013) afirma que as Torcidas Organizadas tem membros de todas as classes sociais, raças, idades e gêneros, caracterizando um perfil "eclético" de modo geral. Para o entrevistado IAV,

\footnotetext{
Boa parte são mais homens, jovens de vinte e tantos anos, mas sempre têm mulheres e crianças, têm até gente casada que é da torcida, e ainda leva o filho junto. Mas idoso e pessoas mais velhas é mais difícil de ter, mas tem também (ENTREVISTADO IAV).
}

A partir dessa narrativa, identifica-se um discurso manifesta a tentativa de transmitir uma imagem socialmente positiva e diversificada sobre o perfil das pessoas que compõem uma Torcida Organizada. $\mathrm{O}$ entrevistado aponta para um ambiente familiar, pacífico, inclusivo e harmônico ao descrever as características dos torcedores organizados da IAV. Embora não se negue a possibilidade de se encontrar idosos, crianças, mulheres (entre outros perfis) nas Torcidas Organizadas, salienta-se que esta diversidade é menos comum do que o apontado pelo entrevistado IAV. Isto porque alguns estudos apontam para outra realidade, a qual há uma predominância de jovens do sexo masculino integrando as Torcidas Organizadas (TOLEDO, 1996; HANSEN, 2007; HOLLANDA; AGUILAR, 2017). Ainda segundo os referidos estudos, este perfil de torcedor organizado, protagonista - da maior parte - dos episódios de violência envolvendo as Torcidas Organizadas presentes em cadernos policiais, programas e jornais esportivos, literatura e em diversos outros meios de comunicação.

O nível socioeconômico pode ser outra característica relevante na construção da identidade de um torcedor organizado. Vale ressaltar que este fator não é um indicativo

licere, Belo Horizonte, v.23, n.2, jun/2020. 
Narrativas de Torcedores Organizados Praticantes de Artes Marciais Acerca da Violência no Futebol

Jonathan Rocha Oliveira, Pauline Peixoto I. Vargas, André Mendes Capraro e Gustavo Elias Zaniol

de diagnóstico para torcedores violentos. A exemplo disso, Santos; Capraro; Lise, (2014) afirma que a invasão da torcida do Coritiba Foot-Ball Club no gramado do estádio do clube em 200912, foi composta por “jovens desregrados de classe média", segundo informações da polícia destacadas no estudo. Por conta disso, evita-se, também, o estigma de que a violência, especialmente no futebol, provém somente das classes mais baixas. Acerca disso, o entrevistado TFI aponta que:

É meio relativo, é uma mistura na verdade, tem gente ali que tem um certo poder aquisitivo, que é uma minoria, mas tem, e a maioria é o 'povão', assalariados que trabalham durante a semana pra ir nos jogos no final de semana, ou durante a semana também, às vezes, ir nos jogos é a única diversão do cara (ENTREVISTADO TFI).

A partir deste discurso, surgem reflexões entre lazer e torcedores de futebol, como o destaque para a inexistência de outras opções de lazer para o torcedor organizado de baixa renda. A discussão acerca do lazer é bastante extensa, e transpõe a proposta deste estudo que, de modo geral, refuta o futebol como única forma de “diversão" - lazer - de um trabalhador (e torcedor). Isto porque, independentemente do nível socioeconômico, existem outras possibilidades de lazer mais econômicas do que assistir aos próprios jogos de futebol, haja vista o aumento substancial no valor dos ingressos. Outro exemplo, é que as próprias agremiações oferecem diversos serviços de lazer.

A estruturação das grandes Torcidas Organizadas é constituída por espaços que funcionam como sede para muitas atividades da própria instituição (HANSEN, 2007) e o oferecimento de serviços como: musculação, lanchonete, escolas de samba, restaurante e academia de Artes Marciais (SILVA et al., 2010; TOLEDO, 1996). Neste sentido, Toledo (1996) sugere que uma rede de sociabilidade sustenta toda atividade de uma Torcida Organizada. De acordo com Hansen (2007), estes "pedaços" - espaços -

12 Cerca de 300 torcedores, maior parte trajando camisetas da IAV, invadiram o gramado após o fim do jogo e o rebaixamento do clube (SANTOS; CAPRARO; LISE, 2014).

licere, Belo Horizonte, v.23, n.2, jun/2020. 
Narrativas de Torcedores Organizados Praticantes de Artes Marciais Acerca da Violência no Futebol

Jonathan Rocha Oliveira, Pauline Peixoto I. Vargas, André Mendes Capraro e Gustavo Elias Zaniol

representam, também, significados para essas agremiações, evidenciando ainda mais o pertencimento de seus integrantes ao grupo.

Conforme o adversário e a importância de uma determinada partida, os torcedores organizados podem motivar mudanças estruturais temporárias na sociedade, como o comportamento social, o bloqueio de ruas e vias de acesso, reorganização do transporte público e deslocamento de contingente policial. Nesse sentido, o entrevistado TOF comenta sobre as formas de deslocamento e de sua rotina em dias de jogos do seu clube...

\begin{abstract}
Depende do jogo. Quando é jogo normal, que não era "jogo de guerra", a gente se reunia duas horas e meia antes no ponto de encontro, e todo mundo ia para o jogo, tranquilo. Agora quando era um "jogo de guerra" como o atletiba13, seis horas da manhã já estava "de pé", já nos reuníamos [...] O dia inteiro. O jogo era umas seis ou quatro horas da tarde, já estava seis da manhã "de pé", ai já se reunia, e começava andar de carro para procurar aonde que "os cara" estavam, ai se achasse, estivesse perto e encontrasse, já íamos para o ataque (ENTREVISTADO TOF).
\end{abstract}

Percebe-se na fala do entrevistado TOF, a utilização do termo "jogo de guerra”, em referência ao confronto contra seu maior rival (Coritiba Foot-Ball Clube), evidenciando uma "rivalidade hostil" como aponta Hansen (2007). Observou também ações premeditadas na busca pelo confronto contra torcedores adversários que pode durar o dia todo, bem como o uso de automóveis. Tais aspectos elucidam um cenário de violência nas Torcidas Organizadas e reforçam a possibilidade de que integrantes participam consciente e deliberadamente de transgressões como "brigar", agredir o outro (torcedor adversário), elevando o status e o poder de seu grupo. Essas ações premeditadas de alguns torcedores organizados podem ser identificadas em um trecho da narrativa do entrevistado TOF, que não apenas corrobora com a busca deliberada por confrontos como ainda sugere um sentimento de prazer nisso.

É só a questão de brigar mesmo. A galera fala 'Ah eu faço pelo meu time', e eu acho isso um pouco de hipocrisia, ele está ali pelo 'tesão' [vontade] de

13 Clássico disputado entre o Clube Athlético Paranaense e o Coritiba Foot-Ball Club.

licere, Belo Horizonte, v.23, n.2, jun/2020. 
estar brigando, de estar no meio da galera, da adrenalina que está rolando [...] (ENTREVISTADO TOF).

O discurso do entrevistado desvela uma série de elementos desafiadores para se pensar a violência nas Torcidas Organizadas de futebol. O primeiro deles é o prazer pela briga devido as sensações que ela pode proporcionar, bem como o sentimento de pertencimento no grupo por "estar no meio da galera", independentemente das ações violentas do grupo. Além disso, para alguns indivíduos como o entrevistado TOF, o futebol, propriamente dito, não é a motivação e nem deve ser utilizado como justificativa para tais transgressões. Embora estas afirmações contribuam para a compreensão dos desdobramentos da violência nas Torcidas Organizadas, ressalta-se que elas não devem ser pensadas como uma verdade absoluta ou de modo generalizado, pois representam apenas a perspectiva de um indivíduo e não o todo. Por outro lado, o entrevistado IAV manifesta outra perspectiva em relação aos desdobramentos e as motivações de um confronto entre torcedores organizados.

\footnotetext{
no momento que a outra torcida aparece na sua frente, não tem muita lógica, você está ali para se defender e defender o patrimônio do seu clube. [...] teve uma vez, que foi em um pós-jogo, com a torcida do Paraná. Nós estávamos no mercado, tínhamos encontrado gente que nem fazia parte da torcida e estávamos dentro do mercado bebendo, então, os torcedores do Paraná [Clube] nos avistaram e vieram para cima de nós, não teve outra saída que não fosse nos defender. Até, que um policial à paisana que estava armado conseguiu separar a briga (ENTREVISTADO IAV).
}

Manifesta-se uma tentativa de justificar seu próprio envolvimento em confrontos neste discurso, pois o entrevistado IAV comenta que participou de episódios de violência para proteger a si e ao patrimônio do seu clube. No entanto, os riscos e os locais de confronto são conhecidos, por vezes comunicados antecipadamente nas redes sociais e, portanto, a condição de vítima ocasional destes torcedores organizados pode ser refutada na maioria dos casos. 
Na sequência, o discurso do entrevistado TFI sugere que alguns indivíduos violentos, integrantes das Torcida Organizas contempladas neste estudo, utilizam o futebol como pretexto para tais transgressões, apontando para o prazer pelas agressões físicas e o distanciamento destes indivíduos com o esporte.

[...] esse pessoal já não está nem mais preocupado com o futebol. Não dá para entender o porquê o "cara" gosta de brigar, ele vai simplesmente por que gosta de bater em alguém, ele quer bater em alguém, então ele busca um motivo, e o motivo que ele encontra é que essa pessoa torce para outro time (ENTREVISTADO TFI).

Apesar dessa narrativa tratar "esse pessoal" como uma parte isolada da Torcida Organizada, não se pode negar o fato de que estes indivíduos de comportamento violento fazem parte das Torcidas Organizadas e, portanto, não deveriam ser dissociados das agremiações, pois isto seria uma tentativa de isentar as Torcidas Organizadas da responsabilidade que tem por todos os seus integrantes.

Soma-se as causas destas ações transgressores, poucas e ineficientes ações de combate a violência (LOPES; REIS, 2017), como o Estatuto de Defesa do Torcedor (BONIN et. al., 2011) destacado anteriormente. O entrevistado TOF relata uma impunidade no que tange atos transgressores entre torcedores de futebol.

É muito difícil acontecer alguma coisa, uma punição mesmo, como a de Joinville [briga generalizada dentro do estádio entre atleticanos e vascaínos em 2013], porque aquela repercutiu muito, então eles ficaram presos por um mês, ficaram tendo que ir na delegacia se apresentar por um bom tempo, ter que fazer trabalho voluntário, mas, é pouco se você for ver. Principalmente em alguns casos, aonde torcedor quase morre, fica vários dias no hospital, e não acontece nada com o infrator (ENTREVISTADO, TOF).

Observa-se que os incidentes ocorridos dentro dos estádios de futebol adquirem maior destaque e, pela facilidade em identificar os envolvidos com os aparatos tecnológicos disponíveis, as medidas cabíveis podem ser tomadas pelas autoridades públicas. Por outro lado, Murad (2017) afirma que o aumento da vigilância dentro das praças esportivas resultou no aumento proporcional da violência fora dos estádios. À medida que os mecanismos de repressão e vigilância se intensificaram no interior das 
arenas esportivas, verificou-se a tendência à irradiação dos conflitos para os arredores e até mesmo para os perímetros urbanos mais afastados dos palcos do jogo (HOLLANDA, AZEVEDO, QUEIROZ, 2014, p. 17). Para o entrevistado TOF:

\begin{abstract}
No estádio é muito difícil [ocorrer confrontos], a polícia está sempre dentro do estádio ou no entorno [pausa]. Agora [também] ficou bem mais difícil de acontecer confusões no terminal [de ônibus], porque a polícia já conhece todos os representantes do comando14. Mas agora onde está acontecendo mais, é dentro das "vilas" [regiões periféricas], o pessoal marca ali, tal hora para se encontrar e ver aonde que os rivais estão, e eles brigam ali mesmo dentro da vila, por que não tem polícia, não tem nada, quando a polícia vem, ela demora para chegar (ENTREVISTADO TOF).
\end{abstract}

De acordo com o entrevistado TOF, os incidentes entre torcedores organizados ocorrem com certa frequência pelos bairros periféricos da cidade e também nos mais diversos espaços públicos. O entrevistado também alerta para o uso das redes sociais na identificação de torcedores organizados rivais.

Se pegar um cara com camiseta de comando, os "caras" acham que é o maior troféu do mundo, principalmente alguns comandos que, por exemplo, nunca perderam uma camiseta, e ficam dando voltas e voltas na região para tentar pegar algum "perdido" ali [...] O problema da torcida organizada, principalmente hoje em dia, todo mundo conhece todo mundo, graças a facebook, redes sociais em geral. Às vezes você vai sair, numa balada, por exemplo, os 'caras' te reconhecem, e já é motivo. Eu já tive que brigar em shopping, por causa de torcida. Fui sair do shopping, na hora que estava no estacionamento, estava eu e mais dois amigos e veio uns cinco 'piás', tivemos que brigar ali (ENTREVISTADO TOF).

As redes sociais também podem ser utilizadas como meios ou ferramentas para as manifestações transgressoras de alguns torcedores organizados, que, identificam, localizam e articulam confrontos com outros torcedores. Disputas simbólicas e materiais por poder, status e o controle das arquibancadas, além de motivar estes enfrentamentos nas Torcidas Organizadas, também denotam conflitos internos nas próprias torcidas. Para Hollanda e Aguillar (2017), estas disputas são resultantes de fatores como: o crescimento e o alargamento territorial das torcidas; o aumento da visibilidade e do status das torcidas; os rendimentos econômicos que a gerência de um grupo como esse

14 Subdivisões dentro das próprias Torcidas Organizadas, de acordo com a região da cidade.

Licere, Belo Horizonte, v.23, n.2, jun/2020. 
Narrativas de Torcedores Organizados Praticantes de Artes Marciais Acerca da Violência no Futebol

Jonathan Rocha Oliveira, Pauline Peixoto I. Vargas, André Mendes Capraro e Gustavo Elias Zaniol

pode oferecer”. A partir de agora, busca-se compreender a presença das Artes Marciais no cotidiano de torcedores organizados.

\section{As Artes Marciais na Perspectiva e Torcedores Organizados}

Alguns estudos (HANSEN, 2007; SILVA et. al., 2010; MURAD, 2017) oferecem algumas contribuições acerca de conexões de práticas marciais no cotidiano de torcedores organizados, dentro das sedes e também fora delas. De acordo com Silva et. al. (2010), algumas Torcidas Organizadas adotam seus símbolos representativos com mascotes trajando vestimentas de Artes Marciais. O referido autor ainda sugere que os espaços/aulas de Artes Marciais oferecidos por algumas Torcidas Organizadas têm a finalidade de atrair mais associados à instituição por meio de algumas atividades de lazer (SILVA et. al., 2010). Viviane Hansen (2007) aponta em sua dissertação etnográfica que a presença de uma academia de treino (Academia Templo da Caveira) ofertando Jiu-Jitsu e o Muay Thai - no prédio dos fundos da sede da TOF em Curitiba, pode estar associada ao uso da força, pregada pela torcida. No entanto, quando questionados pela autora, os responsáveis pelo espaço negaram qualquer tipo de apologia à violência por enfatizar o uso da força nos treinos.

Murad (2017) aponta que determinados integrantes de Torcidas Organizadas são violentos e possuem treinamento em "lutas marciais" (Esportes de Combate com aspectos da marcialidade) como Muay Thai, Jiu-Jitsu, Krav Maga, Caratê, MMA, LutaLivre e, ainda, utilizam armas brancas, excesso de força física e uso de táticas militares na sistematização de suas atividades. Nesta direção, o entrevistado TOF relata que seus primeiros treinos de Artes Marciais ocorriam em sessões nas quais apenas integrantes da Torcida Organizada poderiam participar, simulando os corriqueiros confrontos entre torcedores organizados, como uma espécie de preparação para futuras transgressões contra outras Torcidas Organizadas.

licere, Belo Horizonte, v.23, n.2, jun/2020. 
[...] tinha um 'piá' que tinha uma academia [embora atendesse outros alunos] do comando [leste], que às vezes a galera ia lá pra praticar. Aí treinava 'galera contra galera', era o pessoal da torcida [organizada] [...] a galera treinava com ele, entendeu? Aí juntava todo mundo, a galera da torcida [TOF], daí 'catava uma luvinha', aí em vez de ser 'mano contra mano' dividia a galera e era todo mundo se 'quebrando' (ENTREVISTADO TOF).

Percebe-se a existência de uma busca pelas Artes Marciais por parte de integrantes de Torcidas organizadas para utilizá-las em brigas com outros torcedores organizados. De acordo com Lise (2018), essas "brigas" são evidenciadas em diversas teorizações ao tratarmos o conceito de violência, que pode ser utilizado em vários contextos a partir de diversas formas de ações, comportamentos e fenômenos, como: assassinatos, agressões, verbalizações, assédios, coerções, intimidações, intolerâncias, racismo, preconceitos de gênero, sexismo, bullying, entre tantas outras. Deve-se ressaltar que esta não é uma relação de causa efeito, pois inferir um prisma geral baseado em uma quantidade pequena de relatos seria um equívoco. O entrevistado TOF explica, ainda em seu caso específico, que seu primeiro mestre era o proprietário da academia de Artes Marciais e ele próprio ministrava algumas aulas exclusivas para torcedores organizados de forma distinta das sessões comuns (não exclusivas para torcedores organizados), visando orientar e estimular seus alunos para as brigas contra outros torcedores:

\begin{abstract}
Com os alunos que não eram de torcidas, ele [o instrutor] era normal, ele era um cara totalmente correto, disciplinado, ensinava os alunos a utilizarem as técnicas somente em último caso. Agora, com quem era da torcida, era um treino mais puxado, era um treino mais na 'pegado' mesmo, para a galera saber aonde [sic] está se metendo mesmo. A preparação era para 'sair na mão'. E ali juntava o pessoal que gostava de brigar [...] Às vezes, quando juntavam dez, por exemplo, ele fazia cinco contra cinco, e todos se quebrando ali no meio, lógico, sempre com equipamentos para não machucar ninguém de verdade (ENTREVISTADO TOF).
\end{abstract}

Neste caso, a influência exercida pelo mestre, integrante de uma Torcida Organizada, que aplica sessões de treinamento similares aos bailes de corredor no Rio 
Narrativas de Torcedores Organizados Praticantes de Artes Marciais Acerca da Violência no Futebol

Jonathan Rocha Oliveira, Pauline Peixoto I. Vargas, André Mendes Capraro e Gustavo Elias Zaniol

de Janeiro15, estimula a presença da violência, sendo que as percepções acerca deste conceito são mutáveis e podem variar de acordo com os sentidos, com as temporalidades, com os contextos e com as condições sociais e culturais de determinada sociedade (LISE, 2018). Além disso, ao aderir este tipo de treinamento, estes alunos indicam que visam as Artes Marciais para melhorar seu desempenho nos confrontos entre torcedores organizados, ou seja, sabem o que procuram e são responsáveis pelas consequências de seus atos, dentro e fora da academia. Acerca da diferença na filosofia nos treinos destacada, o fato de ser integrante da Torcida Organizada aponta que o mestre/instrutor, também, se orienta nesta finalidade transgressora nas Artes Marciais e difunde-a como um meio de preparação à violência. Segundo o entrevistado TOF, o fato de seu mestre ser um torcedor organizado é a principal razão para este método diferenciado de treinamento.

É porque ele [mestre] era integrante de torcida, ele está ali por que ele sabe o que ele quer, o cara vai treinar alguém do comando e ele sabe que vai rolar briga, que os caras procuram briga [...] Ele apenas falava para não usarem com gente que não tinha nada a ver, mas apenas com cara de outro comando, que queria brigar. Ele era uma pessoa correta, se ele visse um torcedor desmaiado, ele tirava todo mundo de cima, ele gostava de brigar, por exemplo, em um 'mano a mano' contra o outro cara, sem sacanear o cara (ENTREVISTADO TOF).

Para o entrevistado TOF, o seu mestre tem o status de "pessoa correta" porque não permitia agressões contra alguém desmaiado, no entanto, essa conotação negligencia o fato de o próprio mestre estar envolvido em outros tipos de agressão. É possível, também, que as transgressões sejam fruto de uma necessidade em se provar a superioridade de seu grupo de pertencimento, no caso a Torcida Organizada, fazendo com que se extrapolem os espaços instituídos das academias, ocorrendo rixas em espaços públicos e privados, naquilo que é chamado comumente de "briga de rua"

\footnotetext{
15 Na década de 1990, os bailes de corredor ganharam fama no Rio de Janeiro por proporcionar brigas organizadas, dividindo as pessoas em dois grandes grupos (lado A e lado B). Ver mais em: CYMROT, Danilo. "Ascensão e declínio dos bailes de corredor: $O$ aspecto lúdico da violência e a seletividade da repressão policial". Porto Alegre, V. 4, N.2 - p. 169-179 - julho/dezembro 2012.
}

licere, Belo Horizonte, v.23, n.2, jun/2020. 
Narrativas de Torcedores Organizados Praticantes de Artes Marciais Acerca da Violência no Futebol

Jonathan Rocha Oliveira, Pauline Peixoto I. Vargas, André Mendes Capraro e Gustavo Elias Zaniol

(PASSOS et. al. 2014, p. 1167). Os referidos autores comentam que a construção social da masculinidade e sua constante reafirmações ocorre atrás de demonstrações públicas de violência (PASSOS et. al., 2014), que parece corroborar com o que ocorre em algumas das experiências destacadas de torcedores organizados.

Embora os casos de profissionais desqualificados para o ensino das técnicas de Artes Marciais existam, eles não podem ser compreendidos como um padrão ou como uma maioria, em particular nas Torcidas Organizadas. Além disso, os torcedores organizados também praticam determinadas Artes Marciais, fora do contexto das Torcidas Organizadas, em academias comuns. Assim, o entrevistado TFI ressalta que:

Meu mestre, até hoje, do Caratê sempre frisou o princípio da autodefesa. Só utilizar a técnica, seja ela qual for, se houver uma primeira ação [...] Já no Jiu-Jitsu eu tive dois professores, autodefesa, autocontrole, não partir [ao combate], sempre se defender, e basicamente sempre foi isso que me foi ensinado, nunca utilizar o Jiu-Jitsu como uma demonstração da violência [...] (ENTREVISTADO TFI).

Os valores filosóficos, morais e éticos contemplados pelas Artes Marciais podem nortear a conduta do praticante (ANTUNES, 2009), dentro ou fora das academias e nos demais espaços de prática. A subjetividade desses valores e o tempo de prática de cada indivíduos são fatores preponderantes na percepção de como a Arte Marcial deve ser exercida e o que ela simboliza. Para o entrevistado TFI, as práticas tanto do Caratê, quanto do Jiu-Jitsu, transcendem o esporte como atividades físicas, representando um estilo de vida focado na valorização de aspectos individualizados:

O Caratê é uma filosofia de vida, que eu utilizo como princípio para tudo, a coisa que eu mais tenho que pensar é no cuidado próprio, o meu mestre um dia disse que a primeira coisa que nós temos que pensar na vida, é na primeira pessoa, ou seja, eu mesmo, por que o Caratê é uma autodefesa, primeiro eu tenho que me defender, tenho que estar sempre com o corpo íntegro. E o Jiu-Jitsu é importante, porque apareceu em uma fase ruim, eu estava voltando de lesão, tinha rompido o ligamento e fiquei quase seis meses sem fazer nada, voltei a me sentir bem quando comecei a praticar o Jiu-Jitsu (ENTREVISTADO TFI). 
Narrativas de Torcedores Organizados Praticantes de Artes Marciais Acerca da Violência no Futebol

Jonathan Rocha Oliveira, Pauline Peixoto I. Vargas, André Mendes Capraro e Gustavo Elias Zaniol

O entrevistado TFI compreende que a Arte Marcial pode ser utilizada como uma forma de defender e/ou uma ferramenta de reabilitação física. De acordo com a narrativa, essa noção de autodefesa foi um ensinamento de seu mestre de Caratê. Isto demonstra, mais uma vez, a influência que o professor pode exercer sobre seus alunos, o que alerta para importância da qualificação e capacitação desses profissionais.

Para Fett e Fett (2009) a formação acadêmica dos profissionais envolvidos com os diferentes aspectos do ensino das Artes Marciais é necessária, pois a desinformação e a falta de profissionais qualificados podem criar uma imagem distorcida sobre as Artes Marciais. Vale destacar que as instituições de Ensino Superior já introduziram nos currículos dos cursos de Educação Física, disciplinas que tratam das Artes Marciais (ANTUNES, 2009).

Compreende-se que o comportamento transgressor possa depender, além da conduta do próprio praticante, dos instrutores e mestres das Artes Marciais. A exemplo disso, o caso do entrevistado TOF, em que apesar de seu instrutor também ser um torcedor organizado, seu posto como mestre o torna influente na conduta de seus alunos.

O entrevistado IAV corrobora com esta concepção ao citar as orientações de seu mestre, que não era um torcedor organizado, para não aplicar as técnicas aprendidas e preconizava o respeito e ainda alerta que, apesar das recomendações, alguns torcedores organizados visam as Artes Marciais como instrumente de violência:

\footnotetext{
O professor sempre buscava falar para os alunos terem respeito por qualquer pessoa, nunca ter que usar a Arte Marcial sem necessidade. [Há] pessoas que vão para os jogos apenas para arrumar encrenca, sim, mas isso tem em qualquer torcida, é uma parcela que eu acho que não entendeu a ideologia de uma torcida organizada, ou como ela deveria ser, é uma parcela muito pequena (ENTREVISTADO IAV).
}

Este discurso desvela um prisma em que as recomendações e os valores morais e éticos ensinados podem ser desconsiderados caso haja uma predisposição do praticante em cometer atos de violência. Para justificar essa perspectiva ele afirma que as 
Narrativas de Torcedores Organizados Praticantes de Artes Marciais Acerca da Violência no Futebol

Jonathan Rocha Oliveira, Pauline Peixoto I. Vargas, André Mendes Capraro e Gustavo Elias Zaniol

transgressões são praticadas por uma "minoria". De acordo com o entrevistado TOF, ao comentar acerca de sua mudança de academia e instrutor, apontou para o mestre de Artes Marciais como uma figura que pode influenciar a conduta do aluno positivamente, especialmente, quando a instrução vem é dada por mestres sem relações com Torcidas Organizadas.

Agora, principalmente quando eu troquei de academia comecei a treinar com outro professor, que não tinha nada a ver com torcida, você muda o pensamento, daí, você faz mais por questão de lazer, para praticar alguma coisa, mas de início foi para brigar, mesmo (ENTREVISTADO TOF).

As motivações para se praticar qualquer tipo de Arte Marcial são inúmeras e a busca voluntária pelo risco em um contexto de violência é uma delas. Por outro lado, a generalização destas razões seria equivocada e desconstrutiva, pois de acordo com as narrativas dos três entrevistados, diversas outras causas podem levar um torcedor organizado a praticar Artes Marciais. Há um processo de sociabilidade nas práticas que são produzidas, reproduzidas e reiteradas nesses espaços de pertencimento (PASSOS et. al., 2014). O entrevistado TOF sintetiza que suas motivações, inicialmente, foram para melhorar o desempenho nas brigas entre torcedores organizados:

[O interesse] Veio depois [de entrar para a TOF]. É que, você vê todo mundo fazendo e você vai querendo acompanhar [...] foi mais pela questão da torcida mesmo, de estar ali direto brigando, no meio da confusão, você vai querer melhorar [...] no tempo de torcida, ali por 2010, eu acho, eu pratiquei o Muay Thai por um ano, mais ou menos. O jiu-jitsu eu ia de vez em quando, era só esporadicamente [...] Tem gente que pratica antes [de entrar para a Torcida Organizada], geralmente, você tem um amigo que você sabe que luta e você sabe que é atleticano. Aí, quando tem um atletiba, você chama ele [para os confrontos] e "tal". Muita gente já fica, e muita gente já vê como realmente é e já vai embora [da Torcida Organizada] (ENTREVISTADO TOF).

Segundo Passos et. al. (2014), as práticas físicas voltadas ao desempenho corporal, como as Artes Marciais, possibilitam a exaltação da virilidade, que ocorre em situações polares de vitória ou fracasso por meio da aplicação de técnicas e força física. Fato que pode ocorrer entre torcedores organizados, como foi com o entrevistado TOF. 
Como já destacado, existem outras possibilidades que motivam os torcedores organizados a praticar alguma modalidade de Arte Marcial. O entrevistado TFI afirma que seu pai foi a principal razão:

[...] Caratê eu pratico desde os dez anos de idade, começou como uma ideia de disciplina do meu pai, porque, criança tem que ter disciplina e o Caratê ensina. Também por que meu pai treina Caratê desde 1989. Em 2015, comecei no Jiu-Jitsu e não parei mais, eu gostei muito da ideia das duas lutas. $\mathrm{E}$, nos meus quase nove anos dentro da torcida, nunca precisei entrar em nenhum tipo de confronto, embora saiba que já teve confrontos em viagens TFI com outros torcedores (ENTREVISTADO TFI).

Além do incentivo familiar, o entrevistado IAV sugere que o condicionamento físico também foi o principal fator para sua inserção, bem como a autodefesa...

Eu já pratiquei Judô, Capoeira e Muay Thai [...] comecei a praticar como um esporte, uma luta, para poder ficar em forma, e até, para defesa pessoal [...] Porém, o que você aprende ali, você não pode levar para fora da academia, como no caso das torcidas organizadas, quando acontecem os confrontos (ENTREVISTADO IAV).

Apesar da admissão de que alguns torcedores organizados utilizam técnicas de Artes Marciais em confrontos contra outras Torcidas Organizadas, o entrevistado TOF afirma que estas transgressões ocorrem em situações com menor quantidade de envolvidos e aponta, ainda, que não há diferenças significativas no conhecimento das técnicas durante confrontos generalizados (com muitos envolvidos) das Torcidas Organizadas:

Tanto é que na hora que essa 'galera contra galera', a arte marcial ali não vai fazer tanta diferença, por é galera com pau, pedra, às vezes tem mais de uma pessoa em cima de você. A luta serve mais para quando você encontra os caras no 'mano a mano', ou vai brigar em uma balada, aí ajuda, mas ali no meio da confusão é meio difícil (ENTREVISTA TOF).

O entrevistado IAV corrobora com esta perspectiva, comentando que as técnicas são utilizadas quando há tempo suficiente para assimilação, mas que, frequentemente, outros instrumentos são utilizados.

Assim, se der tempo [de utilizar as técnicas marciais], se você conseguir assimilar tudo, eu acho que dá sim. Tem muitos casos, do pessoal utilizar apenas paus e pedras [ao invés de lutar] (ENTREVISTADO IAV).

licere, Belo Horizonte, v.23, n.2, jun/2020. 
Segundo Passos et. al. (2014), é apontado como fator motivador de brigas em diversos espaços (não aqueles específicos das academias) o fato de não haver possibilidades de disputas entre equipes rivais dentro de competições regradas, ou até mesmo a falta de autocontrole apontada por Elias e Dunning (1992). Em contrapartida, de acordo com os entrevistados, a premissa de utilização das técnicas nestas situações é:

[...] nosso princípio é sempre não buscar brigar, porém, dentro de uma sociedade que brigar faz parte, o pessoal vai te 'atacar', você não vai ficar parado só por que você não quer que as pessoas tenham uma má visão sobre você, e a partir do momento que você se defende, você agride quem está te atacando (ENTREVISTADO TFI).

O entrevistado TFI admite que a autodefesa também seja uma forma de agressão, todavia, os envolvidos nas brigas de Torcidas Organizadas sabem que estão sujeitos a situações de violência em determinados ambientes e, para se defender ou não, essa consciência dos riscos inviabiliza qualquer justificativa. Nesse sentido, o entrevistado TOF admite que buscou estas situações de violência, embora também tenha alegado autodefesa como argumento: "Então, no início quando eu estava na torcida, era pra brigar mesmo, brigar na rua e pra ajudar a me defender." (ENTREVISTADO TOF). Deste modo, estas narrativas elucidam tentativas de transferir a responsabilidade ou amenizar a gravidade destas situações, caracterizando um discurso prévio em que se culpa o outro pelas suas próprias ações.

Vale lembrar que a cidade de Curitiba é um dos principais polos de Artes Marciais no Paraná (e talvez do Brasil), responsável pela formação de diversos atletas profissionais. Nessa direção, Passos et. al. (2014), afirma que alguns lutadores consagrados no $M M A$, tiveram sua formação em Curitiba, como: José "Pelé" Landy, Wanderlei Silva, Murilo "Ninja” Rua, Assuério Silva, Maurício "Shogun” Rua, Anderson "The Spider" Silva e Cristiane "Cyborg". Dada a difusão da Arte Marcial e das Torcidas Organizadas nesta cidade, é possível pensar que alguns lutadores

licere, Belo Horizonte, v.23, n.2, jun/2020. 
profissionais possam ter algum tipo de envolvimento com determinadas torcedores organizados. Em vista disso, os entrevistados mencionam em suas narrativas, possíveis relações ou vínculos de alguns lutadores profissionais com as Torcidas Organizadas, ou que até mesmo já foram integrantes...

Já teve lutador que virou profissional sim, o "Shogun", não vou saber te dizer se ele participava dos conflitos, mas ele fazia parte de um comando, e, eu acho que quando ele viu que poderia se tornar um profissional das Artes Marciais, ele saiu do comando (ENTREVISTADO IAV).

O entrevistado TOF vai além e, de forma mais contundente, afirma:

Têm vários que começaram a brigar na torcida, foram treinar e viraram lutadores, vários. Agora, gente que já lutava antes, é difícil o cara se envolver no meio da torcida, por que ele sabe que vai dar problema, mas tem, tem pessoas que lutam, lutadores profissionais. Não são tão famosos, lógico, mas que às vezes estão no meio da confusão [...] Mas hoje em dia o cara não pode mais se meter nisso, além de qualquer um hoje em dia ter uma câmera, quando o cara é muito graduado, já é considerado como arma branca, se não me engano, ai isso gera muito problema para a pessoa, e ela não iria se envolver ali, mas lutadores pouco conhecidos, e amadores, tem muitos no meio (ENTREVISTADO TOF).

Cabe ressaltar que, de acordo com os relatos apresentados, os lutadores profissionais procuram se afastar das Torcidas Organizadas para evitar uma associação com os atos violentos praticados por alguns torcedores organizados. O estigma negativo atrelado aos torcedores organizados, faz com que o envolvimento de atletas profissionais de uma determinada Arte Marcial possa trazer malefícios a carreiras destes, sobretudo a medida que se desenvolvem profissionalmente.

\section{Considerações Finais}

Em primeiro lugar, é importante esclarecer que as análises realizadas pelos pesquisadores não têm a intenção de generalizar os discursos apresentados ou apontar determinadas perspectivas a uma entidade específica (Torcida Organizada, órgãos públicos ou aos clubes de futebol) citada.

licere, Belo Horizonte, v.23, n.2, jun/2020. 
Narrativas de Torcedores Organizados Praticantes de Artes Marciais Acerca da Violência no Futebol

Jonathan Rocha Oliveira, Pauline Peixoto I. Vargas, André Mendes Capraro e Gustavo Elias Zaniol

Isto posto, em primeiro lugar identificou-se dois tipos principais de manifestações violentas entre torcedores, sobretudo de torcedores organizados. O primeiro diz respeito daqueles que se descontrolam por conta das emoções propiciadas pelo futebol e as tensões contidas nestes indivíduos, ambas capazes de culminar em atitudes violentas. $\mathrm{O}$ segundo tipo sugere que uma parcela minoritária de torcedores organizados, além de torcer, possuem uma predisposição à violência e vislumbram atos violentos premeditados contra outros torcedores.

As narrativas também apontam para autodefesa como justificativa para o seu envolvimento em brigas, entretanto, sabe-se que os torcedores envolvidos nestas situações estão cientes dos riscos que correm e que podem oferecer a sociedade de modo geral. Isto não minimiza a responsabilidade destas agremiações por estes integrantes (violentos), afinal eles também as representam. Ressalta-se que o cotidiano destes torcedores é propício a violência, considerando, também, a ineficiência e as poucas possibilidades das punições e repressões, sejam por parte das autoridades esportivas ou pela própria negligência das Torcidas Organizadas.

Além disso, observou-se a busca pelas Artes Marciais como uma espécie de ferramenta na violência das Torcida Organizadas. Em alguns casos, as Artes Marciais estão presentes até mesmo dentro das sedes das Torcidas Organizadas - algumas chegam a adotar seus símbolos representativos com mascotes trajando vestimentas de Artes Marciais - e são visadas por alguns torcedores organizados com o intuito de aprimorar seus atributos para os confrontos físicos contra outros torcedores organizados.

Vale salientar que, acordo com os entrevistados IAV e TOF, as técnicas de Artes Marciais não exercem tanta influência na performance desses confrontos, devido a circunstâncias de desvantagem numérica, falta de tempo para assimilar o que se passa e a utilização de armas brancas. Os confrontos entre torcedores envolvem artefatos, armas

licere, Belo Horizonte, v.23, n.2, jun/2020. 
Narrativas de Torcedores Organizados Praticantes de Artes Marciais Acerca da Violência no Futebol

Jonathan Rocha Oliveira, Pauline Peixoto I. Vargas, André Mendes Capraro e Gustavo Elias Zaniol

e, ainda, o próprio corpo, e podem acontecer a qualquer hora e local, não só nos dias dos jogos do seu clube (estes possivelmente em menor proporção).

Considera-se imprescindível o autocontrole dos praticantes, pois são os principais responsáveis pela sua conduta fora do espaço destinado à prática, embora a conduta e a filosofia dos professores/instrutores também sejam relevantes para o combate a violência. Neste contexto, sugere-se que alguns alunos/praticantes distorcem os valores destas práticas, e, ainda, quando há o envolvimento do mestre com a Torcida Organizada, a situação é agravada. Por exemplo o caso do entrevistado TOF, no qual o seu primeiro mestre/instrutor incentivava a preparação de torcedores organizados para confrontos entre torcidas, realizando simulações de combate dentro da própria academia.

Para finalizar, destaca-se, ainda, o envolvimento de alguns lutadores profissionais, antes do sucesso profissional, nos confrontos entre torcedores organizados e até mesmo participação efetiva nestes agrupamentos, no entanto, o sucesso profissional e a fama os afasta dessas agremiações devido aos problemas que o envolvimento das Torcidas Organizadas com a violência possa afetar negativamente sua imagem.

\section{REFERÊNCIAS}

ALBERTI, Verena. Manual de história oral. 3. ed. Rio de Janeiro: editora FGV, 2013. AMADO, Janaína; FERREIRA, Marieta de Moraes. Usos e abusos da história oral. 8. ed. Rio de Janeiro, Editora FGV, 2006.

ANTUNES, Marcelo Moreira. A relação entre as artes marciais e lutas das academias e as disciplinas de lutas dos cursos de graduação em Educação Física. EFDeportes Buenos Aires, v. 14, n. 139, 2009.

BARDIN, Laurence. Análise de conteúdo. São Paulo: Edições 70, 2011.

licere, Belo Horizonte, v.23, n.2, jun/2020. 
BONIN, Ana Paula Cabral; MEZZADRI, Fernando Marinho; CAPRARO, André Mendes; CAVICHIOLLI, Fernando Renato. O papel do estado no controle da violência no futebol. Motrivivência, v. 23, n. 37, p. 156-170 Dez./2011.

Ações Públicas e privadas destinadas ao combate a violência no futebol: o caso do jogo entre Coritiba Foot Ball Club e Fluminense FootBall Club. Dissertação (mestrado) em Educação Física da Universidade Federal do Paraná. Curitiba, Mar./2011.

BRASIL. Lei 10.671. Estatuto de Defesa do Torcedor. 3. ed. Brasília: Câmara dos Deputados, Edições Câmara, 2013.

CAVALCANTI, Everton Albuquerque; SOUZA, Juliano de; CAPRARO, André Mandes. O fenômeno das torcidas organizadas de futebol no Brasil - elementos teóricos e bibliográficos. ALESDE, Curitiba, v. 3, n. 1, p. 39-51, 2013.

CASTRO, C. O. (2014, 28 de dezembro). Morte organizada: os bárbaros. O Globo, p.40, 2014.

CORIOLANO, Alina Mira Maria; CONDE, Erick Francisco Quintas. Fanatismo e agressividade em torcedores de futebol. Revista Brasileira de Psicologia do Esporte, São Paulo, v.6, n.2, nov./2016.

CORREIA, Walter Roberto; FRANCHINI, Emerson. Produção acadêmica em lutas, artes marciais e esportes de combate. Motriz, Rio Claro, v.16 n.1 p. 01-09, 2010.

CYMROT, Danilo. Ascensão e declínio dos bailes de corredor: O aspecto lúdico da violência e a seletividade da repressão policial. Porto Alegre, v. 4, N2 - p. 169-179julho/dezembro 2012.

ELIAS, Norbert; DUNNING, Eric. A busca da excitação. Memória e Sociedade. Lisboa, 1992.

EL PAÍS BRASIL. 31 de dezembro de 2017. Disponível em: https://brasil.elpais.com/brasil/2017/12/28/deportes/1514427700_914142.html Acesso em: 19fev. 2019.

FETT, Carlos Alexandre; FETT, Waléria Christiane Rezende. Filosofia, ciência e a formação do profissional de artes marciais. Motriz, Rio Claro, v.15, n.1, p. 173-184, 2009.

GUILHON, Marcelo Faria. Sob a pena da lei: princípios constitucionais, o Estatuto do Torcedor e o cerco às torcidas organizadas no Brasil. In: HOLLANDA, Bernardo Borges Buarque; AGUILAR, Onésimo Rodriguez. Torcidas Organizadas na América Latina: estudos contemporâneos. Rio de Janeiro: 7 letras, 2017.

HANSEN, Viviane. Torcida organizada Os Fanáticos: Relacionamento e sociabilidade. Dissertação (mestrado) em Educação Física da Universidade Federal do Paraná. Curitiba, jun./2007. 
HOLlANDA, Bernardo Borges Buarque; AGUILAR, Onésimo Rodriguez. Torcidas Organizadas na América Latina: estudos contemporâneos. Rio de Janeiro: 7 letras, 2017.

AZEVEDO, Anna Luiza. QUEIROZ, Ana Luisa. Das torcidas jovens às embaixadas de torcedores: Uma análise das novas dinâmicas associativas de torcer no futebol brasileiro. Recorde: Revista de História do Esporte, v. 7, n. 1, janeiro-junho de 2014, p. 1-37.

LISE, Riqueldi Straub. Cerceamentos, coerções e esportividade no Ultimate Fighting Championship (UFC). Tese (doutorado) em Educação Física da Universidade Federal do Paraná. Curitiba, fev./2017.

LOPES, Felipe Tavares Paes; REIS, Heloisa Helena Baldy dos. A política nacional de prevenção da violência e segurança nos espetáculos esportivos: desafios e propostas. Revista Brasileira de Educação Física e Esporte. São Paulo, v. 31, n.1, p.195-208, 2017.

LOWENTHAL, David. Como conhecemos o passado. Projeto História, São Paulo, v. 17, p. 63-201, 1998.

MEZZADRI, F. M.; PRESTES, S. E. C.; CAPRARO, A. M.; CAVICHIOLLI, F. R.; MARCHU JÚNIOR, W. As interferências do Estado brasileiro no futebol e o estatuto de defesa do torcedor. Revista Brasileira de Educação Física e Esporte, São Paulo, v.25, n.3, p.407-16, jul./set. 2011.

MOSKO, José Carlos; MOLETTA JUNIOR, Celso Luiz; FREITAS JÚNIOR, Miguel Archanjo. Estabelecidos e Outsiders na Torcidas Organizadas. Centro Universitário Positivo. Curitiba, out./2000.

MURAD, Maurício. A violência no futebol: novas pesquisas, novas ideias, novas propostas. 2. Ed. Editora Benvirá: São Paulo, 2017.

PASSOS, Daniella de Alencar; PRADO, Rodrigo Cribari; MARCHI JR., Wanderley Marchi; CAPRARO, André Mendes. As origens do "vale-tudo" na cidade de CuritibaPR: memórias sobre identidade, masculinidade e violência. Movimento. Porto Alegre, v.20, n.3, p. 1153-1173, jul./set. 2014.

POLLAK, Michael. Memória e identidade social. Estudos Históricos, Rio de Janeiro, v. 5 , n. 10, p. 200-212, 1992.

REIS, Maria Heloísa Baldy dos. Futebol e violência. Campinas: Armazem do Ipê; 2006.

ROSENTHAL, Gabriele. Pesquisa social interpretativa: uma introdução. $5^{a}$ edição. Porto Alegre: EDIPUCRS, 2014

SANTOS, Natasha; CAPRARO, André Mendes; LISE, Riqueldi. Straub. A invasão no estádio Couto Pereira em 2009: considerações sobre os discursos da imprensa escrita e da torcida organizada. Revista Brasileira de Ciências do Esporte, v. 36, n.3, p. 617625,2014

licere, Belo Horizonte, v.23, n.2, jun/2020. 
SILVA, Silvio Ricardo et al. As Torcidas Organizadas de Minas Gerais. Licere, Belo Horizonte, v.13, n.4, dez./2010.

TOLEDO, Luiz Henrique. Torcer: a metafísica do homem comum. Revista de História, São Paulo, v. 163, p 175-189, 2010.

Torcidas organizadas de futebol. São Paulo: Editora Anpocs, 1996.

UOL. 2017. Disponível em: http://www.uol/esporte/especiais/especial-violenciatorcedores.htm\#tematico-1. Acesso em 27 ago. 2019.

WIEVIORKA, Michel. Um novo paradigma da violência. São Paulo, Tempo Social: Revista de Sociologia da USP, v. 9, n.1, p. 5-41, 1997.

\section{Endereço dos Autores:}

Jonathan Rocha Oliveira

Universidade Federal do Paraná (UFPR)

R. Coração de Maria, 92 - Jardim Botânico

Curitiba - PR - 82.590-300

Endereço Eletrônico: jonathan.cwb@hotmail.com

Pauline Peixoto Iglesias Vargas

Universidade Federal do Paraná (UFPR)

R. Coração de Maria, 92 - Jardim Botânico

Curitiba - PR - 82.590-300

Endereço Eletrônico: piglesiasvargas@gmail.com

André Mendes Capraro

Universidade Federal do Paraná (UFPR)

R. Coração de Maria, 92 - Jardim Botânico

Curitiba - PR - 82.590-300

Endereço Eletrônico: andrecapraro@onda.com.br

Gustavo Elias Zaniol

Universidade Federal do Paraná (UFPR)

R. Coração de Maria, 92 - Jardim Botânico

Curitiba - PR - 82.590-300

Endereço Eletrônico: gustavoeliaszaniol@gmail.com 